bodies of only ten mammals and one tortoise: these preparations and drawings fully showing that the term "supra-renal bodies" used by the Council, and that of "supra-renal capsules" employed by Dr. Harley, the gainer of the prize, were incorrect, for in the great majority of animals these bodies are neither capsular nor above the kidney. Of this fact the proposers of the prize, I believe, were in total jgnorance. Among my preparations, moreover, were several to show valves in the renal veins of many of the animals, so as to prevent the blood from the renal body from regurgi ating to the kidney-preparations entirely new, and not to be seen elsewhere, in this or in any other country. The account of the rejection of these prepara. tions by the Council, to be given in the sequel, will, I trust, be a sufficient excuse for this egotistical flourısh.

In April, 1862, the prize was awarded to Dr. Harley, and on examining his essay I was astonished to find that it wa made up almost entirely of his papers published in the Britivh and Forei!n Reviero, 1858, The Lancet, 1858, and the Pathological Socicty's Transactions, 1857-58, and that no less than forty-four cases by various authors, before published, were in the body of the work, and not in the appendix; that no new experiments or observations had been made since 1858 ; that the few preparations sent with the essay were old and had been exhi bited before; that the drawings were copied from those before published ; and on making a more minute investigation, $I$ dis. covered that more than nine teuths of the essay was copied verbatim from the writers alluded to; and that on thirtecn different occasions Dr. Harley told the arljudicators that he was the author of the essay, which, h? says in the preface, he was not able to get copied, but if he should be successful, he offers to revise us well as copy it. The correctness of the above statements can be verified by anyone who will tike the trouble to examine the essay now in the library of the College of Surgeons.

But the most extraordinary part of the affair remains to be told. When I found that I was an unsuccessful candidate, I wrote to the Council offering $m y$ essay and preparations to the College, for the benefit of those, I said, who might hereafter investigate this mysterious and interesting subject, and who might, perhaps, profit by my errors. I said, moreover, that according to law, the essay and preparations, if not claimed before three years, would become the property of the College, but that I was anxious to anticipate this event, and give them at once, if the Conncil would accept them.

No allusion of any kind was made in this letter to the illegality of the aucard. (I have mislaid the copy.) The Council, in their reply, declined, under the circumstances, to accept the essay and the preparations; and so anxious wore they to get rid. of them that they sent them to my house; but luckily I happened to be at home, and refused to take them in, on the plea, that on making the offer I expressly stated that I was anxious to anticipate the event that must legally occur in three years.

I am curious to know what will be done with them at the expiration of three years. The admittance of medical reporters to the Council chamber will be a guarantee, I hope, that the essay and preparations will not share the igneous fate of better things at this establishment.

I will, after the publication of this letter, with your permission, send you my conclusions (as seen in the essay now at the College) respecing the "Structure and Use of the Renal Bodies." The matter yet requires a great deal of sifting and ventilating, but I presume to think that I have made the foundation of the inquiry a little more secure for future investigators.

$$
\text { I am, Sir, yours obediently, }
$$

Parliament-street, Nov. $1863 . \quad$ EDWARDS CRISP, M.D.

\section{DEATH FROM CHLOROFORM.}

\section{To the Editor of The LanceT.}

SrR, - The last number of your journal contains what is said to be a report of my evidence at the inquest on the body of Ellen Smith, who died from the effects of chloroform, and on whom I was about to perform an cperation. As that report is, in many respects, not only an entire misrepresentation of what I said, but of the proceedings at the inquest, and imputes to me views which I never have held, may I be allowed space in your columns for its correction?

First, with regard to the inquest. It is said, "after a long consultation the jury returned a verdict that Ellen Smith died of chloroform, and that there was no blame to the medical men." Now, Sir, to my knowledge, there was no semblance of a consultation between the juryunen. The foreman collected their individual opinions, and was ready with his verdict in about the time that it took him to walk around the table for that purpose; and there was not a moment's hesitation on the part of any one of those gentlemen with respect to it. The word "manslaughter" was not used in my hearing throughout the inquest; and I am sure I should have heard it had it been employed, as reported.

Iu the second place, my remarks on the administration of chloroform are altogether incorrectly given. After giving a statement of what took place, I was asked by the coroner whetber any one had continuous "charge" of the pulse. I said that the pulse was repeatedly felt both by $M r$. Worley and nyyself during the very few minutes that the inhalation was going on. but not continuously. The coroner then (as reported) "dwelt in strong terms upon the omission of the medical men continuously to watch the pulse;" to which I replied, that I did not deem it necessary; that I had seen chloroform given hundreds of times, in private and in public; and that on no one occasion had $I$ ever seen such a practice observed as a rule. I, however, ad mitted (contrary to the report) that the pulse should on every occasion be most carefully attended to ; but that at the same time there were other indications to be noted, which were, perbaps, of equal importance-viz., the features, the state of the eyes, lips, breathing, \&c. \&c. ; that, in fact, all should have due attention, according to the pecnliaritits of the patients respectively, and their varying conditions under the influence of the agent. I contended, moreover, that these points of observation must be left to the discretion of the administrator. I hare, I may just remark, since learned, by repeated observation, that duing the spasmodic stage which usually precedes that of complete insensibility, it is impossible to keep up continuous watching of the pulse; and it was during this stage, in the unfortunate case under consideration, that the patient died.

Although I could not convince the coroner-not, I believe, a medical man-I was pleased to hear from some of the gentlemen of the jury, after the inquest was over, that my observations were perfectly satisfactory to the whole of that body; and this must also have been apparent to the coroner, before he proceeded to sum up, from the remarks made by one and another of the jurors in support of my views as the inquest proceeded.

In this deplorable case, every possible care was taken both by Mr. Worley and myself; and I am quite sure no continuous watching of the pulse during the process of inhalation would have been effectual in saving the life of this young lady. She died during the convulsive stage, and the collapse was sudden. Tho immediate cause of death was, in my opinion, palsy of the involuntary muscles; for I observed the pupils suddenly to dilate, then contract, and then to dilate again fully and permanently, and all within the space of two or three seconds. The heart's walls were found, after death, to be perfectly flaccill.

I most fully concur in your general remarks on the administration of this uncertain and dangerous agent, aad trust we shall soon have from the Chloroform Commi tee some definite rules for our guidance, which may serve very materially to lessen the painful risk which, with our present knowledge, attends its administration.

I am, Sir, your obedient servant,

Finsburs-place South, Nov. 1863.

JoHN GAY, F.R.C.S.

** The report in question was given in THE LANCET in verbatim extracts from the public journals. - ED. L.

\section{$D \cup B I I N$}

(FROM OUR OWN CORRESPONDENT:)

I TRUST that I shall be excused in returning to the subject of introdnctory lectures, as but scant justice would be done to our Dublin School did I omit mention of the address delivered at the opening of the winter session at the House of Industry Hospitals, by Dr. Corrigan, President (for the fifth time) of the College of Physicians. These hospitals are three in numberthe Richmond Surgical, the Whitworth Merlical, and the Hardwicke Fever,-and for years past have oc supied a foremost rank amongst our educational establishments. Here it was that Carmichael first opposed himself to the then current views upon venereal; that $O$ 'Beirne taught the value of tobacco in the treatment of tetanus, and demonstrated the utility of that long enema tube which still bears his name; that Adams laid 